\title{
User Experience Design for Brain-Computer Interfaces to Support Interaction in Points of Interest
}

\author{
Lizbeth Peralta-Malváez, J. Alfredo Sánchez and Ofelia Cervantes \\ Depto. de Computación, Electrónica y Mecatrónica, \\ Universidad de las Américas Puebla, \\ San Andrés Cholula, Puebla, México \\ \{lizbeth.peraltamz, alfredo.sanchez, ofelia.cervantes\}@udlap.mx
}

\begin{abstract}
This paper discusses the potential of brain-computer interfaces (BCI) in the interaction between users and objects in points of interest in a city. We present an initial design of the user experience with BCI, aimed to include users with disabilities but also to enhance the experience of the general public. This design includes a physical space to be conditioned specifically for BCI so users can interact with certain objects in a museum, as well as enhancements throughout the museum based on BCI. We report results of a formative evaluation of the main design concepts.
\end{abstract}

Keywords: Brain-Computer Interfaces, Points of Interest, Objects of Interest, Augmented Reality, Accessibility.

\section{Introduction}

Many museums have been incorporating innovative technologies, such as multimedia kiosks, audio tours and interactive displays [1-3]. Unfortunately, people with some disability cannot always enjoy these enhancements. For example, in Mexico only two museums have programs for blind people. For people with hearing or speech disabilities, only guided visits are offered using sign language [4].

In this context, brain-computer interfaces (BCI), which make it possible for users to interact with computer systems through sensors of brain activity, offer great opportunities for addressing the needs of disabled users as well as for enhancing functionality available to the general public. This paper explores the use of BCI for interacting with objects of interest (OIs) in a museum, in the context of the REAUMOBILE project, discussed below.

The remainder of the paper is organized as follows: In Section 2, related work with BCIs is presented; Section 3 further explores the needs of users with disabilities in the context of POIs. Section 4 discusses an initial user experience design involving BCI, whereas Section 5 presents results of a formative evaluation of the proposed design, which relied on feedback provided by two focus groups and three individual interviews. Finally, Section 6 discusses ongoing work and the conclusions we have drawn thus far. 


\section{Related Work}

A brain-computer interface $(\mathrm{BCI})$ is a communication system that allows the user to send messages to a computer with only brain activity [5]. In general, a BCI works as follows: Neurons are connected to one another by dendrites and axons. When they start to work, small electric signals are generated by ions on the membrane of each neuron. Although paths followed by signals are insulated, some can be detected by mechanisms such as electroencephalograms (EEG) or magnetic resonances. Signals can be interpreted by a computer program and associated to activities as required by the user [6].

BCI applications are often related to the goal of supporting users with disabilities. Some examples include research to help patients control their prostheses and improve signal reception. Nevertheless, BCIs can be used in other areas [7-10]. For the purposes of this paper, device control, gaming and entertainment are areas of particular importance and thus are discussed in further detail below. We also summarize salient work and issues on usability and user experience involving BCI.

Device control. Various techniques have been developed in order to improve control by the user in a BCI system. One example is the technique allows the user to rely on only three commands: left, right and foot Motor Imagery (MI: brain signs are generated when users imagine the movement of their own limbs). In addition, there are two types of navigation: free (the user can select POIs) and assisted (the user can rotate the camera in order to find a specific POI) [11]. Another example is Command Selection Training (CST), which determines the subject's initial response to an oscillating visual stimulus. The brain produces a corresponding response and this response can then be used to create a BCI command [12].

Gaming and entertainment. Control in games that rely on BCIs can be based on the user's affective state or on the user's brain activity [13]. In the first case, the system can detect the experience of the users in certain tasks by sensing their cognitive activity. In the second case, researchers are using mostly MI, Event-Related Potential (evoked by external stimuli to which the brain responds automatically), evoked by artificial stimuli and oscillatory rhythms of the brain activity [14]. Games such as World of Warcraft, Second Life and Son of Nor can be used now with BCIs [15], [16].

Usability and User Experience with BCI. Research on usability with BCIs might be just as important for their acceptance and widespread usage as their technological aspects. Usability components in this context present some specific traits [14]:

Learnability and memorability: Sometimes performing a mental task to communicate with the computer is new for most of the people. It has to be made clear to the users what is expected from them if they want to use a BCI.

Efficiency: Some BCI applications can adapt the way they present information or react to user input depending on the user's psychological state.

Errors: Error Related Negativity (ERN) can be used in order to detect when users are aware of their errors and undo previous movements.

Satisfaction: This is mostly related with the ease with which the user could learn and memorize the control of the BCI and with which accuracy they could control the system. 
Although there has been progress in BCI applications, they still exhibit common problems that can affect the user experience (UX). For example, users get exhausted from the intense concentration they have to undergo in order to use a BCI system; some distractions, like noise, can detonate unwanted commands; the environment can produce internal effects such as changes in the user's state; users cannot use headsets for more than one hour; the sensor connection can take some time; there are chemical processes which the EEG cannot sense; the signal may be weak and prone to interference [6], [14], [17].

\section{Use Scenario for BCI}

REAUMOBILE is a project aimed to disseminate the cultural heritage and to improve the experience of visitors and residents of a smart city. The project is exploring the use of augmented reality, social networks and the interaction with existing sources of media content of points of interest (POIs) such as museums, archeological sites and religious buildings [18]. REAUMOBILE provides a platform that can be used in mobile devices for visitors to have access to various information layers and interactive features associated with objects of interest in POIs. Normally, anyone with a smartphone is able to use REAUMOBILE functionalities, but in order to be more inclusive, there are issues this project needs to consider: What happens with a person who cannot hold a smartphone or a tablet due to physical disabilities? What happens if a user cannot see or has visual limitations? How can someone on a wheelchair enjoy the experience offered by REAUMOBILE? What about users with hearing and speech disabilities?

\section{UX Design for a BCI Scenario}

Taking into account the challenges posed by users with disabilities, we have produced an enhanced scenario for a museum in which BCIs are introduced. Fig. 1 illustrates our scenario by means of a storyboard (Fig. 1).

As noted in the figure, a family that includes a disabled person decides to visit a museum. A special area in the museum has been adapted to allow users to experience various aspects of their objects of interest via BCI. This space can be considered an interactive area for anyone interested, regardless of whether or not users have some disability. In the BCI area, users can interact with specific OIs to find additional information, to situate OIs in the context of the collection, and to manipulate 3D models of the objects. This area should have the following characteristics (also illustrated in the storyboard):

-Total silence, so users do not get distracted with noise of other museum visitors or events.

-Engaging BCI applications, which may include videogames and collaborative learning functionality. These should offer multiple skill levels so users can practice, 
train the BCI and eventually become experts. Naturally, these applications will be related to the OIs available in the area.

-Access to in-depth information about OIs as well as translation mechanisms for OIs that are described in a language different from the user's.

-3D models for some OIs so users can rotate them, play animations, scale them up or down, and view their relationships with other OIs.

-Access to consulting museum services, such as location of wheelchair ramps, elevators and other services required by visitors.

The specific case of a game that can be operated via BCI is illustrated with more detail in Fig. 2, relying also on a storyboard (Fig. 2). With simple facial expressions such as winking, users can select whether they want to perform a task or play a game. Confirming the action can be accomplished by another pre-defined facial expression. For users with visual disability, the system may produce voice expressions indicating which button is being selected. The storyboard illustrates the case for a user who selects a game ("Arrange"), and then is presented with options to complete level 0. This level has two main objectives: the player gets used to the headset and to perform all the tasks only by focusing his mind on the expect result, and the system is trained in order to identify the player's brain patterns and activities. In our example, the user must visualize the desired movement with a cube, such as "up", "down", "left", "right", etc. After level 0 is completed, the selected game can be played more smoothly.

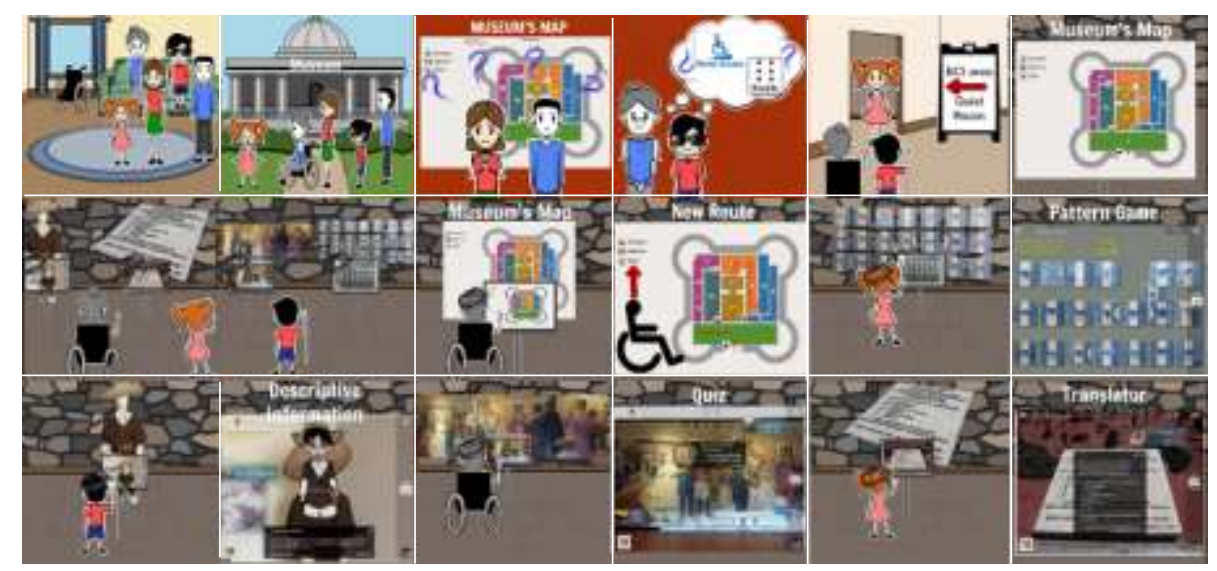

Fig. 1. Storyboard of the BCI area.

\section{Formative Evaluation}

In order to gather more information and different points of view regarding our proposed scenario, we interviewed 11 users ( 6 male, 5 female) with the following characteristics: Five with visual disability, two with motor disability, three without a disability and one with hearing and speech disability. Two focus groups (the people 
with visual disability and the group without a disability) and three individual interviews were conducted in different days for two reasons: the difficulty of transferring people with visual and motor disability to the same place and the availability of the 11 users.



Fig. 2. Storyboard of the pattern game.

All subjects answered the same questionnaire, which included questions about the following: frequency of visiting social places (parks, downtown and more), difficulties they have when they go to those places, and if they have used a technology adapted to their needs (question only for the people with a disability). After applying the questionnaire, technical concepts were briefly explained, such as BCI and AR. Then, the proposed scenario endowed with BCI was presented. Finally, questions about which kind of activities and games users would like to add to the system, about the display of the museum's services and about how to encourage people to go to the museum (Table 1).

The main ideas were explained in a different way for each type of user: For users with visual disability we described verbally every detail, like what kind of objects the area will have, the incorporation of large screens next to OIs, the expected interaction sequences, and so on. We also followed this approach for one of our subjects with motor disability due to her limited availability, as she was interviewed over the phone. For people without a disability, another person with motor disability, and a subject with hearing and speech disabilities, we used the storyboard presented in the Figure 1. The following results were obtained:

-People with a disability reported the following difficulties: They depend on family support to transport them or guide them, they find few services that consider their disability (ramps, parking, etc.) and they generally have to make a great effort to communicate with other people. The main difficulties found by people without a disability are related to the distance to POIs and public transportation.

-Some features they would add to our design include: Audio- based, more detailed and portable information (some would like to take it to their homes); exchanging comments upon tour completion (whether they liked the area, what was their favorite object and why, etc.); and cooperative interaction.

-Games suggested by users include linguistic games such as riddles or word play, memory, cooperative games, treasure hunting and virtual routes of the museum. 
-All of the users liked the idea that of being able to generate a route with the map and see what services the museum has.

-Ten of the eleven participants would use the BCI system; only one user explained that he had not visited a museum before, so he could not answer this question.

- Some of the users with a disability insisted that the museum should provide a web site adapted to their needs. One suggested that on certain days, the government or the museum's administration could rent some buses in order to take disabled users to these historical places.

Table 1. Main information of the focus groups and personal interviews.

\begin{tabular}{|c|c|c|c|c|c|}
\hline User & Disability & Age & Schooling & Frequency of visiting places & $\begin{array}{c}\text { Technology for their } \\
\text { needs }\end{array}$ \\
\hline 1 & V & 84 & Undergraduate & Relatives & B,S \\
\hline 2 & V & 71 & Graduate & Parks, trips, galleries & B,S,C \\
\hline 3 & V & 56 & Teacher & Downtown and relatives & B,S \\
\hline 4 & V & 54 & Elementary & Church and therapy & B,S \\
\hline 5 & V & 28 & Secondary & None & Books \\
\hline 6 & M & 82 & Not available & Therapy & Sign language \\
\hline 7 & M & 42 & Not available & Once a week & - \\
\hline 8 & DM & 24 & Not available & 5 times a month & - \\
\hline 10 & N & 22 & Undergraduate & Once a month & - \\
\hline 11 & N & 23 & Undergraduate & 3 times a month & \\
\hline
\end{tabular}

Disability: $\mathrm{V}=$ Visual; $\mathrm{M}=$ Motor, $\mathrm{DM}=$ Deaf-Mute, $\mathrm{N}=$ None;

Technology: $\mathrm{B}=$ Braille, $\mathrm{S}=$ Speakers in the computer, $\mathrm{C}=$ Cell phone.

\section{Conclusions and Future Work}

This paper has discussed initial work in designing the user experience for interactive systems that involve brain-computer interfaces. Rather than focusing on the functionality offered by existing BCI technologies, we have started by working with potential users and learning about their needs, capabilities and limitations. Although they were enthusiastic about the proposed idea, people with disabilities expressed their concern about the infrastructure of the museums that is not appropriate for them. This is one of the reasons they do not go to these places and they also explained that they do not want to be all the time in their houses or in their rehabilitation centers. They want to coexist with other people without being excluded. At the same time, they want to learn more about history, science and technology without their disability limiting them in this regard.

As for future work, we plan to integrate the observations of our users. Low and high fidelity prototypes will be created and usability and user experience tests in the museum will be made. For an actual implementation, we currently are considering the use of the Emotiv EPOC neuroheadset, as its Software Development Kit (SDK) 
provides three detection libraries that will be useful [19]: Expressiv Suite (interprets facial expressions in real time and uses an avatar that imitates them), Affectiv Suite (shows real time changes in the subjective emotions experienced by the user) and Cognitiv Suite (evaluates a user's real-time brainwave activity to discern the user's conscious intent to perform distinct physical actions on real or virtual objects).

Finally, museums should publicize their BCI facilities among schools and rehab centers for a better interaction with their objects and insist that anyone can use it, regardless of whether or not they have a disability.

\section{Acknowledgments}

The authors would like to acknowledge the support received from Conacyt through the REAUMOBILE project number 192321. We also express our gratitude to IECEDEVI, Ilumina Tu Vida, the Inclusion Department of UDLAP, for welcoming us and allowing us to learn about their needs. Centro Sustenta was key in introducing the authors to the first two institutions.

\section{References}

1. Conaculta.: Aprovecha el INAH las tecnologías multimedia para difundir el patrimonio cultural. (2012). [Online]. Available FTP: http://www.conaculta.gob.mx/detallenota/?id=20789\#.U7ke3vl5MkM

2. Conaculta: Conaculta presenta la app del Atlas Cultural de México y guías turísticas culturales. (2012). [Online]. Available FTP: http://www.conaculta.gob.mx/detallenota/?id=24358\#.U7keJvl5MkM

3. Conaculta.: Garantizar el uso social e interactivo de multiplataformas digitales, demandan especialistas. (2014). [Online]. Available FTP: http://www.conaculta.gob.mx/detallenota/?id=34760\#.U7ka2_15MkM

4. Conaculta.: Acciones de accesibilidad en beneficio de personas con discapacidad. (2011). [Online]. Available FTP: http://www.inah.gob.mx/especiales/5374-acciones-deaccesibilidad-en-beneficio-de-personas-con-discapacidad

5. Lotte, F.: Brain-Computer Interfaces for 3D Games: Hype or Hope? Proceedings of the 6th International Conference on Foundations of Digital Games (FDG '11). ACM (2011). 325327.

6. Grabianowski, E.: How Brain-computer Interfaces Work. (2007). [Online]. Available FTP: http://computer.howstuffworks.com/brain-computer-interface.htm.

7. Van Erp, J., Lotte and F., Tangermann, M.: Brain-Computer Interfaces: Beyond Medical Applications. (2012). [Online]. Available FTP: http://lifesciences.ieee.org/articles/114brain-computer-interfaces-beyond-medical-applications

8. Krishnaswamy, K. and Kuber, R.: Toward the Development of a BCI and Gestural Interface to Support Individuals with Physical Disabilities. Proceedings of the 14th international ACM SIGACCESS conference on Computers and accessibility (ASSETS '12). ACM (2012). 229-230.

9. Marchesi, M. and Riccò, B.: BRAVO: A BRAin Virtual Operator for Education Exploiting Brain-Computer Interfaces. CHI '13 Extended Abstracts on Human Factors in Computing Systems (CHI EA '13). ACM (2013). 3091-3094.

10. Anthony, S.: Berkeley researchers replace passwords with passthoughts by reading your mind. (2013). [Online]. Available FTP: http://www.extremetech.com/computing/152827berkeley-researchers-authenticate-your-identity-with-just-your-brainwaves-replacepasswords-with-passthoughts 
11. Lotte, F. et al.: Exploring Large Virtual Environments by Thoughts Using a BrainComputer Interface Based on Motor Imagery and High-Level Commands. Presence: Teleoper. Virtual Environ. 19, 1 (February 2010), 54-70.

12. Chung Chen, S. et al.: The Use of a Brain Computer Interface Remote Control to Navigate a Recreational Device. (2013). [Online]. Available FTP: http://www.hindawi.com/journals/mpe/2013/823736/

13. Nijholt, A.: BCI for Games: A 'State of the Art' Survey. Proceedings of the 7th International Conference on Entertainment Computing (ICEC '08). Springer-Verlag (2008). 225-228.

14. Plass-Oude Bos, D. et al.: Brain-Computer Interfacing and Games in Brain-Computer Interfaces: Applying our Minds to Human-Computer Interaction. Springer. (2010). 149-178.

15. Neurogadget.: Emotiv-Compatible Son of Nor game successfully hits its kickstarter goal. (2013). [Online]. Available FTP: http://neurogadget.com/2013/06/03/emotiv-compatibleson-of-nor-game-successfully-hits-its-kickstarter-goal/8131

16. Neurogadget.: Second Life avatars controlled via Brain-Computer Interface. (2011). [Online]. Available FTP: http://neurogadget.com/2011/07/08/second-life-avatars-controlledvia-brain-computer-interface $/ 2303$

17. Pires, G. et al.: Evaluation of brain-computer interfaces in accessing computer and other devices by people with severe motor impairments. (2012). [Online]. Available FTP: http://www.sciencedirect.com/science/article/pii/S1877050912007946

18. REAUMOBILE.: Proyecto REAUMOBILE: Realidad Aumentada con dispositivos móviles. Proyecto CONACYT- OSEO no. 192321. (2014). [Online]. Available FTP: https://dl.dropboxusercontent.com/u/7594275/ReauMobile/in dex.html

19. Emotiv.: Emotiv EPOC User Manual Headset and software setup for your Emotiv EPOC neuroheadset. (2014). [Online]. Available FTP: https://emotiv.zendesk.com/hc/enus/articles/201222455- Where-can-I-find-a-user-manual- 